\title{
Reconstruction of three centuries of annual accumulation rates based on the record of stable isotopes of water from Lomonosovfonna, Svalbard
}

\author{
Veijo A. POHJOLA,,${ }^{1}$ Tõnu A. MARTMA, ${ }^{2}$ Harro A. J. Meijer, ${ }^{3}$ John C. MOORE, ${ }^{4}$ \\ Elisabeth ISAKSSON, ${ }^{5}$ Rein VAIKMÄE, ${ }^{2}$ Roderik S.W. VAN DE WAL ${ }^{6}$ \\ ${ }^{1}$ Department of Earth Sciences, Uppsala University, Villavägen 16, S-752 36 Uppsala, Sweden \\ E-mail:veijo.pohjola@geo.uu.se \\ ${ }^{2}$ Institute of Geology, Tallinn Technical University, Estonia pst 7, 10143 Tallinn, Estonia \\ ${ }^{3}$ Centre for Isotope Research, Groningen University, Nijenborgh 4, 9747 AG Groningen, The Netherlands \\ ${ }^{4}$ Arctic Centre, University of Lapland, P.O. Box 122, FIN-96101 Rovaniemi, Finland \\ ${ }^{5}$ Norwegian Polar Institute, Polar Environmental Centre, N-9296 Tromso, Norway \\ ${ }^{6}$ Institute of Marine and Atmospheric Research, Utrecht University, P.O. Box 80005, 3508 TA Utrecht, The Netherlands
}

\begin{abstract}
We use the upper $81 \mathrm{~m}$ of the record of stable isotopes of water from a $122 \mathrm{~m}$ long ice core from Lomonosovfonna, central Spitsbergen, Svalbard, to construct an ice-core chronology and the annual accumulation rates over the icefield. The isotope cycles are counted in the ice-core record using a model that neglects short-wavelength and low-amplitude cycles. We find approximately the same number of $\delta^{18} \mathrm{O}$ cycles as years between known reference horizons, and assume these cycles represent annual cycles. Testing the validity of this assumption using cycles in $\delta \mathrm{D}$ shows that both records give similar numbers of cycles. Using the $\delta^{18} \mathrm{O}$ chronology, and decompressing the accumulation records using the Nye flow model, we calculate the annual accumulation for the ice-core site back to AD 1715. We find that the average accumulation rate from 1715 to 1950 was on average $0.30 \mathrm{~m}$ w.e. Accumulation rates increased about $25 \%$ during the later part of the 20 th century to an average of $0.41 \mathrm{~m}$ w.e. for the period 1950-97. The accumulation rates show highly significant 2.1 and 21 year periodicities, which gives credibility to our time-scale.
\end{abstract}

\section{INTRODUGTION}

The use of ice cores as climatic and environmental archives is increasing. They used to be only considered valuable when recovered from the dry-firn areas in the heart of Antarctica and Greenland, but more careful site selection and improved analysis techniques have now started to establish reliable icecore records within the percolation zone in the Arctic and at high-elevation snowfields at lower latitudes (e.g. Koerner, 1997).

One of the most important tasks in ice-core analysis is to establish the chronology of the core. The dating techniques generally used in ice-core analysis include: (a) flow models, (b) counting cycles of seasonally varying parameters in the core, (c) using reference horizons, and (d) using unstable isotopes with known radioactive decay (Paterson, 1994). Most of these methods have their pros and cons, and it is unusual to obtain a good ice-core chronology relying on only one of them. The best results come from combining as many parameters from the ice core as possible (Hammer and others, 1978; Meese and others, 1997; Eichler and others, 2000).

The most used annual marker in ice cores is the seasonal variation of stable isotopes in water $\left(\delta^{18} \mathrm{O}\right.$ and $\left.\delta \mathrm{D}\right)$, and in particular $\delta^{18} \mathrm{O}$. Despite the development in understanding of the insoluble-dust and ion-chemistry deposition records (Koerner, 1977; Hammer and others, 1978; Legrand and Mayewski, 1997), $\delta^{18} \mathrm{O}$ and $\delta \mathrm{D}$ are still the most common tools for finding the depth/time relation in ice cores. Although excellent conditions for preservation of annual cycles of $\delta^{18} \mathrm{O}$ and $\delta \mathrm{D}$ exist in areas such as central Greenland, the isotopes sometimes fail to record an exact chronology due to missing annual layers in the record, or because intra-seasonal variations create spurious cycles (e.g. Bolzan and Strobel, 1994; Shuman and others, 1995). The reasons behind this are to be found in both pre- and post-depositional processes (Jouzel and others, 1997; Pohjola, 2002).

Here we use the upper $81 \mathrm{~m}$ of the $\delta^{18} \mathrm{O}$ and $\delta \mathrm{D}$ record from a $122 \mathrm{~m}$ long ice core from the icefield Lomonosovfonna, central Spitsbergen, Svalbard, to determine a more precise chronology of the core than is available through reference horizons and flow modelling. We also reconstruct the annual accumulation rates for the icefield.

\section{THE ICE-GORE RECORD AND ICE-CORE SITE}

The $122 \mathrm{~m}$ deep ice core was drilled in May 1997 and penetrated to within about $5 \mathrm{~m}$ of the bed. The ice-core site, drilling procedure, analytical techniques, climate at the drill site and the background to the project are described in Isaksson and others (2001). The drill site was at the summit of the $600 \mathrm{~km}^{2}$ Lomonosovfonna icefield (1250 m a.s.l.; Fig. 1), with an average annual temperature of about $-12^{\circ} \mathrm{C}$. Latent heat from percolating meltwater has raised the temperature of the ice column to about $-2.5^{\circ} \mathrm{C}$ (Van de Wal and others, 2002). 


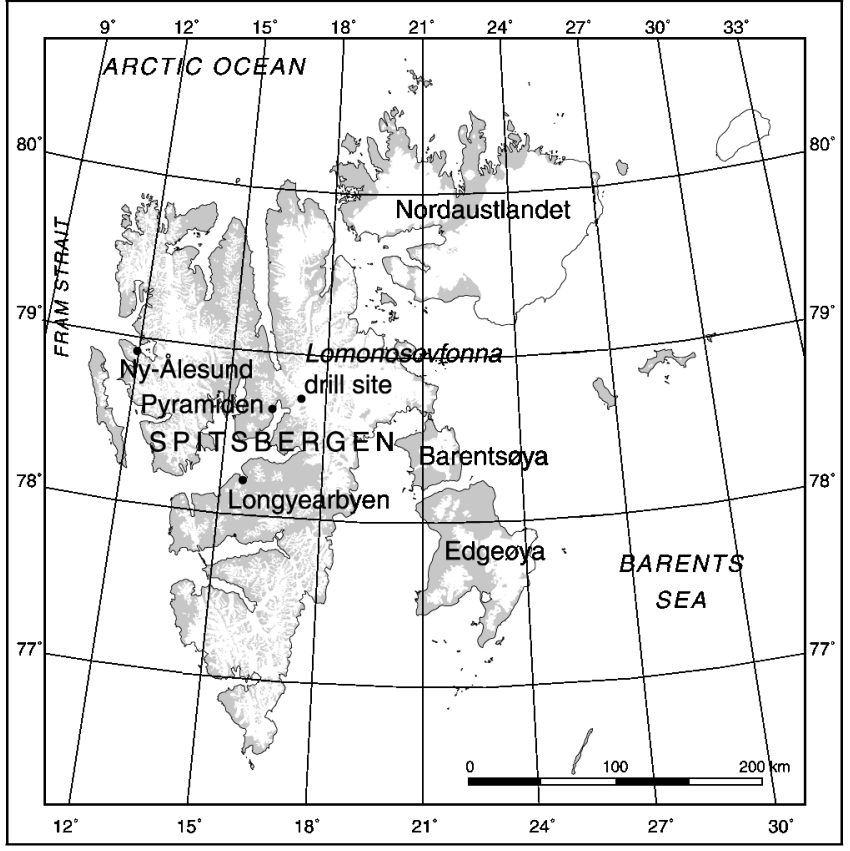

Fig. 1. Map over Svalbard showing Ny Alesund, Longyearbyen and the ice-core site Lomonosovfonna on the island of Spitsbergen. The white terrestrial area is ice-covered terrain.

From stratigraphic studies it was estimated that about $25 \%$ of the snowpack melts in a median year, with an increase to about $33 \%$ melt during the last century (Pohjola and others, 2002). Despite melting of the snowpack and infiltrating meltwater, there were no signs of reorganization of the $\delta^{18} \mathrm{O}$ and $\delta \mathrm{D}$ in the ice strata due to percolation. Pohjola and others (2002) show that only slight depletion of $\delta^{18} \mathrm{O}$ and $\delta \mathrm{D}$ was found in infiltrated ice facies compared with firn layers and bubbly ice facies.

The ice-core data used here are the $\delta^{18} \mathrm{O}$ and $\delta \mathrm{D}$ record from the upper two-thirds of the core. $\delta^{18} \mathrm{O}$ is available in a continuous array of $0.05 \mathrm{~m}$ samples from $0-81 \mathrm{~m}$ depth, and $\delta \mathrm{D}$ in two shorter continuous arrays $(5.0-10.1$ and $17.4-36.1 \mathrm{~m}$ depth) and a series of discontinuous samples (also in $0.05 \mathrm{~m}$ intervals) (Fig. 2). The analytical uncertainty $(\varepsilon)$ of $\delta^{18} \mathrm{O}$ is $\pm 0.1 \%$, and of $\delta \mathrm{D} \pm 1.5 \%$. The upper part of the ice core was analyzed for radioactive isotopes (Pinglot and others, 1999), and at $18.5-18.95 \mathrm{~m}$ (12.95-13.34 m w.e.) the 1963 bomb horizon was found. The sulphate record was investigated for volcanic horizons, and only one event stood out: the Laki (Iceland) eruption of 1783 at $66.8 \mathrm{~m}$ (54.82-54.87 m w.e.) (Kekonen and others, 2002).

\section{The potential of $\delta^{18} \mathrm{O}$ and $\delta \mathrm{D}$ as annual time markers at the drill site}

One prerequisite for using stable isotopes $\left(\delta^{18} \mathrm{O}\right.$ and $\left.\delta \mathrm{D}\right)$ in water as annual time markers is that the isotopic record shows a distinct annual cycle. The isotopic record reflects various processes: the regional temperature variation, regional hydrological cycle and atmospheric circulation dynamics, as well as ocean surface temperature and its relation to ocean circulation dynamics (for further details see Jouzel and others, 1997; Hoffmann and others, 1998). In other words, a rather complex dynamical environment influences $\delta^{18} \mathrm{O}$ and $\delta \mathrm{D}$ in the water vapour, which is later deposited as snow on the icefield. The hydrological cycle and the atmospheric circulation over the Atlantic Ocean sector of the Arctic show a pro-

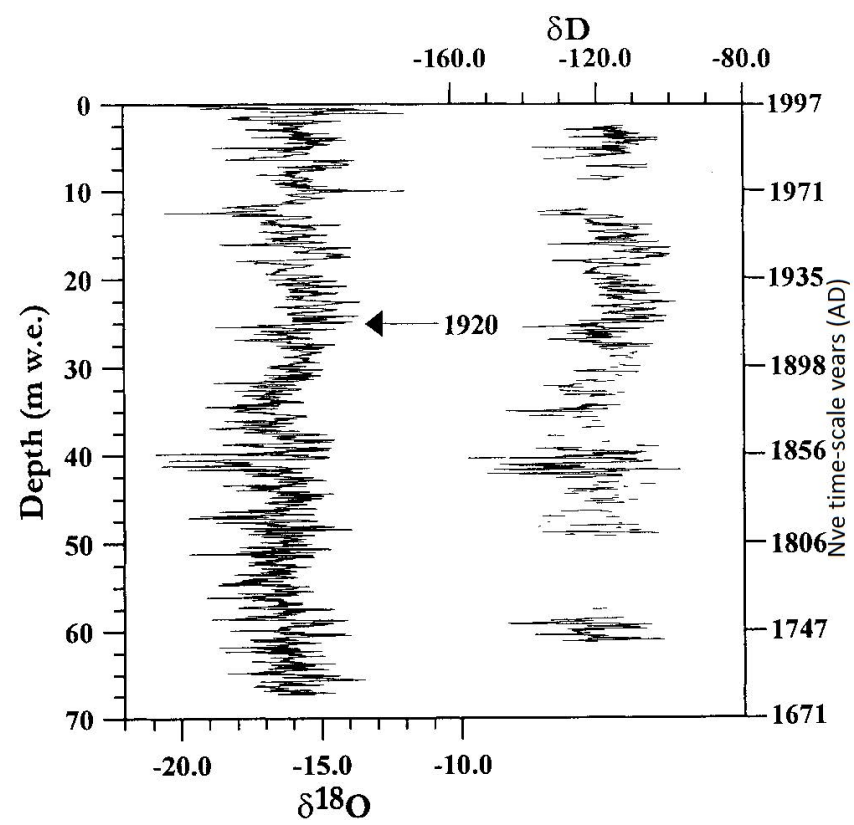

Fig. 2. The ice-core record of $\delta^{18} O$ (oxygen isotope ratio) (left) and $\delta D$ (hydrogen isotope ratio) (right) at 0-81 m core depth.
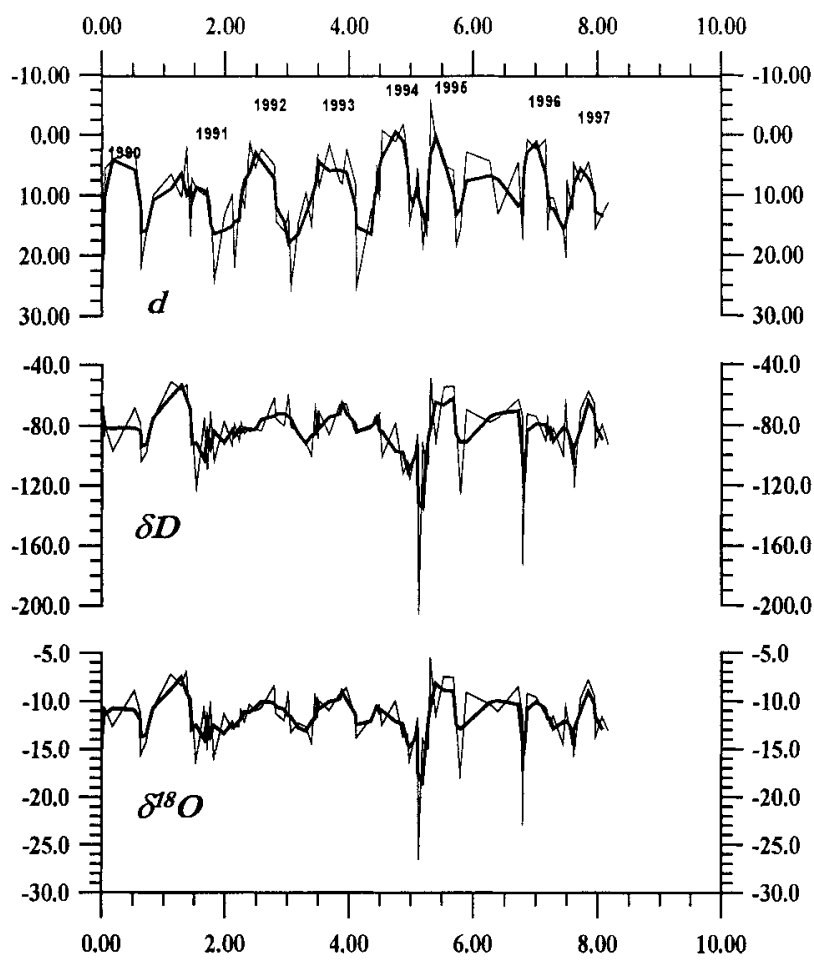

Firn thickness (m)

Fig. 3. The record of $\delta^{18} O, \delta D$ and deuterium excess (d) at $\mathcal{N y}$ Alesund, 1990-97. The thinner lines are the monthly record (http://wrwreiaea.org/programs/ri/grip/gripmain.htm), and the thicker lines are a three-point moving average. The monthly data are converted into metres of firn by adding each month's precipitation to the time (depth) axis. The density of the firn is $400 \mathrm{~kg} \mathrm{~m}^{-3}$ throughout the pack. This forces dry and isotopically extreme periods to have a lower weighting in the depth/ time axis, similar to that recorded in an ice column. The annual label is positioned at June in each year in the horizontal axis. Note that the horizontal axis is not real depth, but can be viewed as thickness from a reference point in a firn pack starting Fanuary 1990. 
nounced seasonal cycle. This is imprinted as detectable annual cycles of $\delta^{18} \mathrm{O}$ and $\delta \mathrm{D}$ in precipitation collected at the coastal station of $\mathrm{Ny}$ Ålesund, west-central Spitsbergen, situated about $100 \mathrm{~km}$ west of the ice-core site (Fig. 1). The location of Svalbard between mild maritime Atlantic air masses and colder Arctic air masses introduces intra-seasonal noise into the record. Diffusion of the isotopic signal will smooth out most of these short-period events, and the annual cycles will be most pronounced in the ice-core record (Johnsen, 1977; Whillans and Grootes, 1985). The smoothing effects of the three-point moving average in Figure 3 show a simplified illustration of the effects of diffusion on the Ny Ålesund record.

The isotopic record from $\mathrm{Ny}$ Ålesund shows distinct annual cycles in most years. Only the 1995 and 1996 cycles show a less clear character, which might have been difficult to detect in a real snow/firn pack. Thus we find that $\delta^{18} \mathrm{O}$ and $\delta \mathrm{D}$ have an annual cycle in this region which we assume is also present over Lomonosovfonna. Therefore, we expect to find $\delta^{18} \mathrm{O}$ and $\delta \mathrm{D}$ annual cycles in the ice-core record, as long as post-depositional processes, such as vapour-driven diffusion, have not eliminated this signal.

\section{RESULTS}

\section{Calculation of isotope cycles}

The model used to identify annual cycles in $\delta^{18} \mathrm{O}$ and $\delta \mathrm{D}$ is based on the simple criterion that each time $\partial X / \partial z$ $\left(X=\delta^{18} \mathrm{O}, \delta \mathrm{D} ; z\right.$ is distance down-core) changes sign, a (seasonal) half-cycle is found, and the algorithm delivers the depth of the presumed seasonal extrema. In order to avoid cycles of smaller wavelengths than annual lengths, two criteria must be met: (1) amplitude of cycle $>$ analytical uncertainty $(\varepsilon)$, (2) half-wavelength of cycle $>$ detection length $(l)$, where $l$ is the search window, which is the minimum thickness of a seasonal layer. The algorithm can only find cycles having more than two points per cycle, obeying the Nyquist criterion (Press and others, 1992). The model is discussed further in Pohjola and others (2002).

Since the ice column is affected by gravitational spreading, vertical strain will thin the older (deeper) layers. Nye (1963) provided a simple function to correct for the vertical strain such that $L_{\mathrm{z}}=L_{\mathrm{s}}(z / H)$, where $L$ is the layer thickness, $H$ is the ice thickness in $\mathrm{m}$ w.e., and subscripts $\mathrm{s}$ and $z$ represent the values at the surface and at a height $z$ (in $m$ w.e.) above the bed. The length of the search window $(l)$ was adjusted according to the Nye thinning model, giving a gradually decreasing $l$ with depth. The relation between strain and depth presented by Nye (1963) leads to the Nye time-scale, $t=-(H / a) \ln (z / H)$, where $t$ is time and $a$ is accumulation rate (Dansgaard and Johnsen, 1969).

We first use the $\delta^{18} \mathrm{O}$ record to calculate the chronology, since the $\delta \mathrm{D}$ record is not available for the full depth interval. To control the model we use the two established reference horizons of AD 1783 and 1963. We also use an extra datum of AD 1920 based on a more subjective feature fitting than the 1783 and 1963 horizons. In the temperature record from Longyearbyen (1911-97) (Nordli and others, 1996) there is a pronounced increase in air temperatures, with the midpoint at 1920. We assume this will be reflected in the isotopic data, and place this date in the middle of the pronounced increase of $\delta^{18} \mathrm{O}$ in the isotope record (Fig. 2). The other two reference horizons with the Nye time-scale also gave approximately this age to the isotope feature indepen-
Table 1. Comparison of depths to reference horizons based on cycle-counting with various values of the minimum thickness of the search layer $l_{\mathrm{s}}$

\begin{tabular}{cccccc}
\hline \multicolumn{1}{c}{$l_{\mathrm{s}}$} & $\begin{array}{c}\text { Number } \\
\text { of cycles }\end{array}$ & 1963 & \multicolumn{4}{c}{ Datum horizon } \\
& $\mathrm{n}$ & mw.e. & mw.e. & m w.e. & years AD \\
mw.e. & $\mathrm{n}$ & & & & \\
\hline 0.100 & 242 & 12.83 & 28.47 & 62.97 & 1755 \\
0.080 & 262 & 11.02 & 26.82 & 59.47 & 1735 \\
0.060 & 288 & 11.02 & 24.74 & 54.02 & 1709 \\
0.062 & 283 & 11.02 & 25.26 & 54.98 & 1714 \\
& & & & & \\
\hline
\end{tabular}

Note: The datum horizons used were: 1783 (54.82-54.87m w.e.), 1920 (24.94 m w.e.) and 1963 (12.95-13.34 m w.e.).

dently, but it is useful to have this reference layer as an additional check on our cycle counting.

Table 1 shows the results of counting annual cycles in the $\delta^{18} \mathrm{O}$ record using various values of $l_{\mathrm{s}}$. The best overall result is obtained using a value of $0.062 \mathrm{~m}$ w.e. It is apparent that no single value of $l_{\mathrm{S}}$ would give a perfect result with all datum horizons placed at their correct depths. The time/depth relationship was also investigated by Kekonen and others (2002) using the Nye time-scale. They found that accumulation rates must have increased in the last part of the 20th century in order to explain the position of the Laki and 1963 bomb test markers. To give the datum horizons their correct depths, we use $l_{\mathrm{s}}=0.10 \mathrm{~m}$ w.e. in the $1963-97$ interval, and $l_{\mathrm{S}}=0.07 \mathrm{in}$ the deeper parts of the core. The obvious explanation for the better match obtained by using a larger $l_{\mathrm{s}}$ in the upper $18.5 \mathrm{~m}$ is that accumulation rates were higher in this part of the core. Additionally, the younger ice has more high-frequency variability in the record than in the lower part of the core, as the

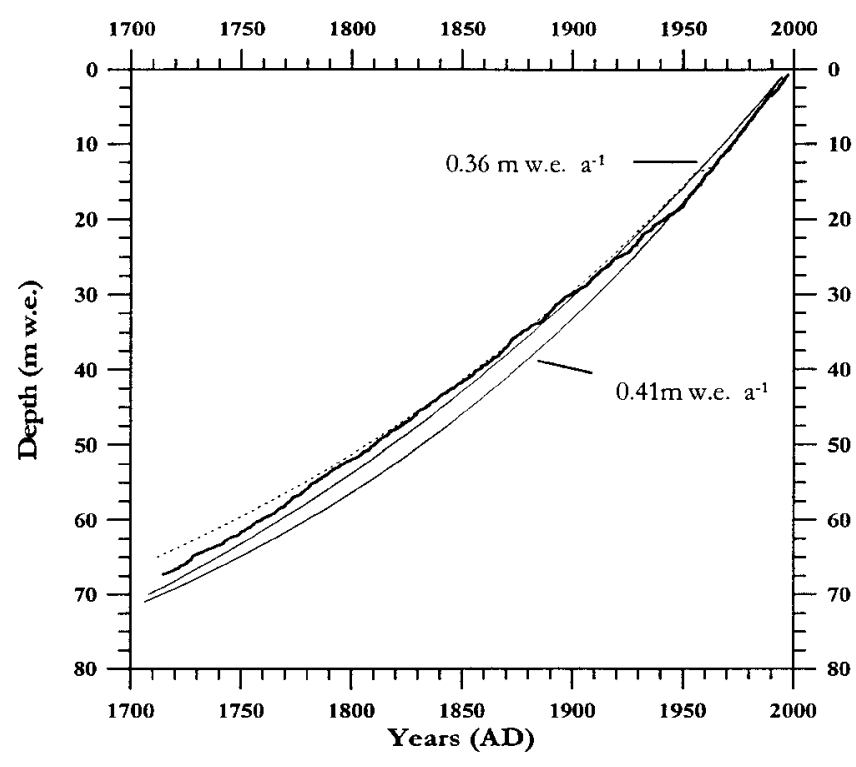

Fig. 4. The depth/age relation in $m$ w.e. of the upper $81 \mathrm{~m}$ of the Lomonosovfonna ice core, calculated by using annual cycles of $\delta^{18} \mathrm{O}$ (thick line). The thin curves show the depth/age relation based on the Nye model using an apparent accumulation rate of $0.36 \mathrm{~m}$ w.e. $a^{-1}$ (upper) and $0.41 \mathrm{~m}$ w.e. $a^{-1}$ (lower). The dashed curve shows the depth/age relation based on the Nye model using an accumulation rate of $0.42 \mathrm{~m}$ w.e. $a^{-1}(1996-$ 63) and $0.31 \mathrm{~m}$ w.e. $a^{-1}(1963-1715)$. 

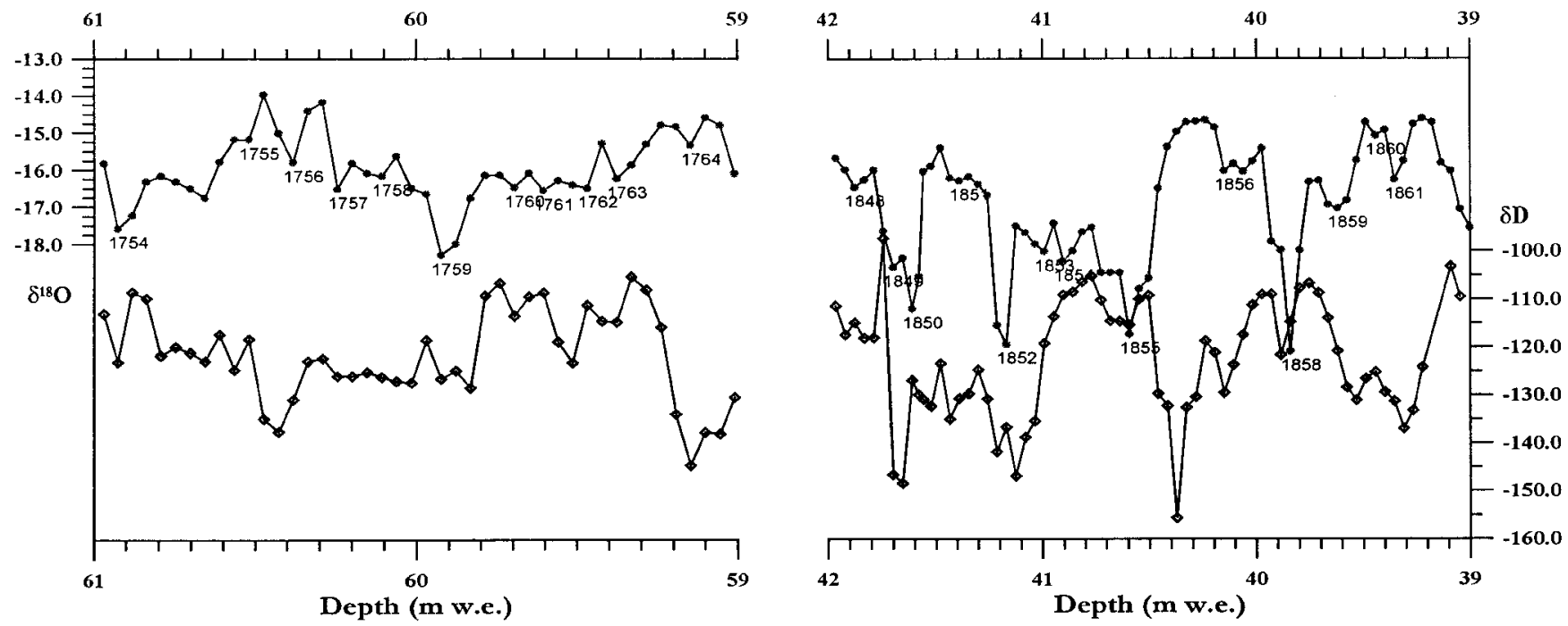

Fig. 5. The isotope cycles (upper curve $\delta^{18} \mathrm{O}$, lower curve $\delta D$ ) shown in two depth intervals centred on about AD 1750 and 1850.

The crosses mark the midpoint of each sample.

older part of the record is smoothed by diffusion. This could lead to our search method detecting shorter than annual cycles if $l_{\mathrm{S}}$ is too small. A larger $l_{\mathrm{S}}$ gives fewer cycles per unit core.

Figure 4 shows the calculated depth/age relation in $m$ w.e., and compares the derived scale to time-scales calculated from the Nye time-scale.

It is generally recommended in ice-core studies that each annual cycle should contain at least eight samples. (e.g. Paterson, 1994, p. 333). With increased thinning down the core, our sampling size of $5 \mathrm{~cm}$ samples will fail to meet that criterion at some depth. In Figure 5, we study the sampling density at two depth intervals centred around AD 1750 and 1850. We find that the upper interval barely meets this criterion, and that some years are thinner and contain fewer samples. The lower interval has even fewer samples per year. We do know the number of years between our dated horizons, and presume that each year will be shown as an isotopic cycle. By restricting our cycle counting to layers that simply satisfy the basic Nyquist sampling theorem (Press and others, 1992) we count cycles as years that contain fewer than the ideal 6-8 samples, but which contain sufficient points to define a cycle (i.e. three points). Below our last reference horizon (Laki) at $54.8 \mathrm{~m}$ w.e. we introduce a higher uncertainty in the timescale. Also as depth increases, the thickness of each cycle is less precisely determined, since the vertical extent of each cycle will be constrained by fewer samples.

\section{Validation of $\delta^{18} \mathrm{O}$ chronology by comparing $\delta^{18} \mathrm{O}$ and $\delta \mathrm{D}$ cycles}

The ice-core chronology, or the depth/time relation, shown in Figure 4 is based on the position of the seasonal extrema in the $\delta^{18} \mathrm{O}$ record. Figure 3 shows that the $\delta \mathrm{D}$ record has annual cycles similar to the $\delta^{18} \mathrm{O}$ record. We can use this to test the results of our $\delta^{18} \mathrm{O}$ cycle counting, since within the same depth interval the $\delta \mathrm{D}$ and the $\delta^{18} \mathrm{O}$ record should show the same number of cycles. $\delta \mathrm{D}$ is only available in two long continuous intervals in the $0-81 \mathrm{~m}$ part of the ice core, $5.02-$ $10.17 \mathrm{~m}$ w.e (interval A) and 12.11-27.72 mw.e (interval B). We find that we obtain similar numbers of cycles in the $\delta \mathrm{D}$ record and in the $\delta^{18} \mathrm{O}$ record, although the $\delta \mathrm{D}$ cycles are somewhat fewer $(7-10 \%$ fewer $\delta \mathrm{D}$ cycles; Table 2$)$.

The explanation for the differing results using $\delta \mathrm{D}$ and $\delta^{18} \mathrm{O}$ is probably the higher ratio of signal to analytic uncertainty $(\varepsilon)$ in $\delta^{18} \mathrm{O}$ than in $\delta \mathrm{D}$. In stating this we assume that $\delta \mathrm{D}$ and $\delta^{18} \mathrm{O}$ in the precipitated record are similar to each other (e.g. Fig. 3). Post-depositional diffusion of the signals cannot account for the fewer $\delta \mathrm{D}$ cycles, since the $\delta^{18} \mathrm{O}$ signal would decay faster than $\delta \mathrm{D}$ (Johnsen and others, 2000). However, this discrepancy in numbers of isotopic cycles can give an estimate of the uncertainty of the method $( \pm 10 \%)$.

We also tried to use the deuterium excess, $d$, defined as $\left[\delta \mathrm{D}-\left(8 \delta^{18} \mathrm{O}\right)\right]$, to count annual cycles. However, the results were poor, mainly because $\varepsilon$ becomes a quite large number for $d(2.3 \%$ ), which is about $50 \%$ of the average amplitude in $d$ in the ice-core record. In order to use $d$ cycles as annual markers, it seems the diffusion has to be calculated, and then the data must be back-diffused (Johnsen, 1977; Bolzan and Pohjola, 2000; Johnsen and others, 2000).

\section{Calculation of accumulation rates at Lomonosov- fonna summit back to AD 1715}

As the ice-core chronology has been established, the accumulation rates over the icefield can be reconstructed. Figure 6 shows the thickness of the annual layers over the period 1715-1996, based on the $\delta^{18} \mathrm{O}$ cycle chronology. The decrease of annual layer thickness (apparent accumulation rate) back with time is affected by the thinning of the layers with depth. In order to decompress the annual layers, we used the Nye model for vertical thinning (Paterson, 1994). To decompress the annual layers we used an accumulation rate of $0.36 \mathrm{~m}$ w.e. $\mathrm{a}^{-1}$, based on the depth of the 1963 reference horizon (Pinglot and others, 1999). The thinned (measured) and

Table 2. Comparison of number of cycles found in the $\delta D$ and the $\delta^{18} \mathrm{O}$ record in the two different intervals where both were analyzed

\begin{tabular}{cccc}
\hline Interval & $l_{\mathrm{s}}$ & Cycles $\delta^{18} \mathrm{O}$ & Cycles $\delta D$ \\
& mw.e. & $n$ & $n$ \\
\hline $\mathrm{A}$ & 0.10 & 10 & 9 \\
$\mathrm{~B}$ & 0.07 & 56 & 52 \\
\hline
\end{tabular}




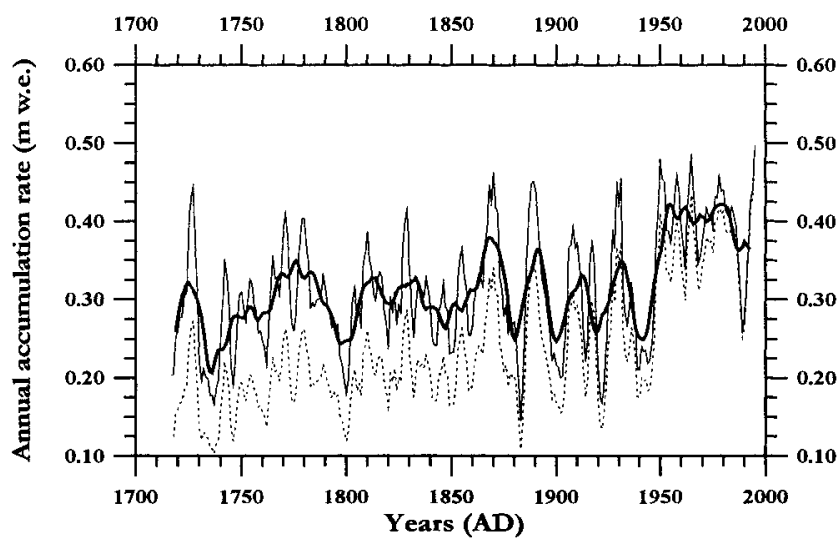

Fig. 6. The calculated annual accumulation rates, AD 17151997. The lower curve (dashed line) shows the thinned annual thickness from the ice core. The upper curve (thin line) is the decompressed annual thickness, giving the accumulation rates. Both curves are plotted using a weighted 5 year running mean. The thicker line is the 11year running mean of the decompressed accumulation rates.

the decompressed (calculated) accumulation rates are shown in Figure 6. The decompression of the data introduces an uncertainty to the time (depth) gradient of the accumulation rate. The Nye model assumes a constant vertical strain rate, while other models have more sophisticated solutions (Dansgaard and Johnsen, 1969; Raymond and others, 1996). An imperfection of all these models is that they fail to take into account variations in accumulation rate. However, time-averaged accumulation rate influences the thinning rate more than does accumulation variance.

The general trend of accumulation rates seen in Figure 6 is an average accumulation rate of about $0.30 \mathrm{~m}$ w.e. $\mathrm{a}^{-1}$ from the 18 th century to the mid-20th century, with a $\sim 25 \%$ increase to an average of about $0.42 \mathrm{~m}$ w.e. $\mathrm{a}^{-1}$ in the later part of the 1940s. The accumulation rate in the lower part of the series is the most sensitive to uncertainty in the decompression, and the long-term gradient may then be somewhat in error. However, the date at $81 \mathrm{~m}$ depth using a Nye model with both the 1963 and the 1783 reference horizons (providing two accumulation rates in different periods) is 1704 (Kekonen and others, 2002), which is very close to the 1715 date found from the isotope cycles. The 10 year discrepancy between the methods in the extrapolation of some 70 years beyond the Laki marker suggests a combined error in both methods of about $15 \%$, which is consistent with our earlier estimate of approximately $10 \%$ error in the cycle-counting method. The large increase of accumulation rate in the mid-20th century is certainly real, and probably shows another mode of precipitation pattern over the icefield. Ground-penetrating radar surveys over the surrounding glaciers show that internal reflection horizons are also indicative of a late-20th-century rise of about $10 \%$ in accumulation rates (Pälli and others, in press).

Another feature visible in the accumulation data, which is independent of the decompression model, is the periodicity of the accumulation rates. Singular spectrum analysis (SSA; e.g. Vautard and others, 1992), using a window of 60 years and Monte Carlo significance testing with 1000 statistically similar surrogate series, was performed to make robust estimations of non-linear trends and quasi-periodic components. SSA is particularly useful for finding oscillations that are not strictly periodic, such as may be expected if there are some

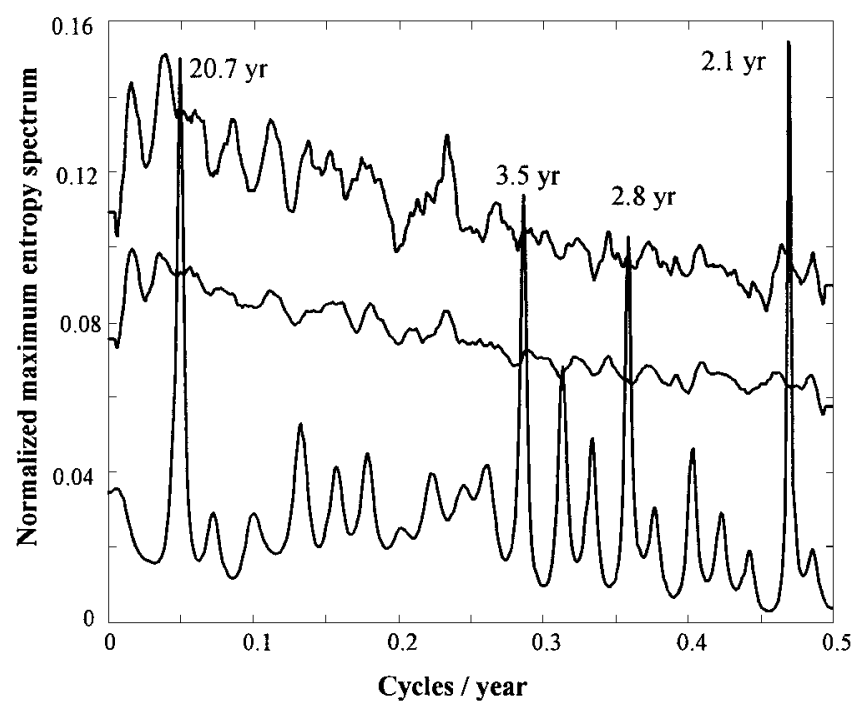

Fig. 7. Normalized maximum entropy spectrum (of order 50) of the accumulation rate (lower curve). The $99 \%$ and $95 \%$ significance levels against red-noise estimates from 1000 firstorder autoregressive Monte Carlo simulations are shown in the two uppermost curves. The peaks at 20.7, 3.5, 2.8 and 2.1 years are clearly significant.

errors in dating the ice core year-by-year. As SSA operates in the time rather than the frequency domain, errors in dating contribute to an overall lowering of the signal-to-noise ratio, while still allowing quasi-periodic signals to be found and their significance tested. There is no significant longterm trend in accumulation in the decompressed data. SSA shows quasi-periodic signals significant at the 99\% level against both white and red noise in the quasi-biannual (QB: 2.1 year) band accounting for $3.4 \%$ of the variance. There is also a highly significant signal with a period of 20.7 years accounting for $6.3 \%$ of the variance. Additional signals significant against red noise were found at 3.5, 2.7 and 2.1 year periods. The maximum entropy spectrum in Figure 7 is a more traditional view of the frequency content of the accumulation-rate record, and the significant power peaks are at the same frequencies as found by the more robust SSA technique. While the 2-4 year power band may be speculated to have an El Niño-Southern Oscillation origin, the 20.7 year period signal has not been shown in other Arctic records, as far as we know. SSA of the large-scale atmosphere circulation patterns over the Arctic and Atlantic- the North Atlantic Oscillation and the Arctic Oscillation (Thompson and Wallace, 1998) - shows power in the QB band. Similar results are seen in North Atlantic sea surface temperatures, and ice conditions in the Baltic Sea (Jevrejeva and Moore, 2001). Our finding of the two highly significant periodic signals, especially the well-known QB signal, adds confidence to our dating.

\section{CONGLUSIONS}

We can construct an ice-core chronology from Lomonosovfonna using isotope cycles as time markers. The continuously sampled precipitation at a nearby coastal station shows pronounced annual cycles in stable isotopes in water, which correspond to similar-magnitude isotope cycles found in the ice-core data.

We further find that diffusion of the isotope signal has 
damped the seasonal amplitudes in the ice-core record, so that the amplitude of seasonal cycles in deuterium excess is of the same magnitude as the analytical uncertainty. The $\delta^{18} \mathrm{O}$ cycles are still detectable in the record, at least down to $80 \mathrm{~m}$ core depth, due to their much lower analytical uncertainty. The thinning of annual layers suggests that the lower $40 \mathrm{~m}$ of the core should be sampled with higher resolution in order to reveal annual cycles. From the Nye time-scale we find that an average annual layer at $100 \mathrm{~m}$ depth would be $6 \mathrm{~cm}$ thick. This suggests that we need a sample size of about $2 \mathrm{~cm}$ to reveal annual layers at this depth.

The calculated annual accumulation rates over the icefield show a general trend of lower accumulation from the 18th century to the mid-20th century, when accumulation rates increased rapidly. We also find significant periodicity in the accumulation record at 2.1 and 21 years.

\section{ACKNOWLEDGEMENTS}

We are grateful for the work done by everyone involved in the Lomonosovfonna Ice Core Project. E. Huss, J. Ivask, T. Jauhiainen, M. Karczmarska, H. Samuelsson, C. van der Veen and J. Vähviläinen are thanked for sampling assistance. A. Igesund is thanked for the Svalbard map. We are grateful to the Finnish Academy, the Nordic Council of Ministers, the Norwegian Polar Institute, Stiftelsen Ymer-80 and the Swedish Natural Science Council for funding. Comments from two referees and the editor E. Steig are much appreciated.

\section{REFERENGES}

Bolzan, J. F. and V. A. Pohjola. 2000. Reconstruction of the undiffused seasonal oxygen isotope signal in central Greenland ice cores. 7. Geophys. Res., 105(C9), 22,095-22,106.

Bolzan, J. F. and M. Strobel. 1994. Accumulation-rate variations around Summit, Greenland. F. Glaciol., 40(134), 56-66.

Dansgaard,W. and S. J. Johnsen. 1969. A flow model and a time scale for the ice core from Camp Century, Greenland. F. Glaciol., 8(53), 215-223.

Eichler, A. and 7 others. 2000. Glaciochemical dating of an ice core from upper Grenzgletscher (4200 m a.s.l.). F. Glaciol., 46(154), 507-515.

Hammer, C. U., H. B. Clausen, W. Dansgaard, N. Gundestrup, S. J. Johnsen and N. Reeh. 1978. Dating of Greenland ice cores by flow models, isotopes, volcanic debris, and continental dust. F. Glaciol., 20(82), 3-26.

Hoffmann, G., M. Werner and M. Heimann. 1998. Water isotope module of the ECHAM atmospheric general circulation model: a study on timescales from days to several years. 7. Geophys. Res., 103(D14), 16,871-16,896.

Isaksson, E. and 14 others. 2001. A new ice-core record from Lomonosovfonna, Svalbard: viewing the 1920-97 data in relation to present climate and environmental conditions. F. Glaciol., 47(157), 335-345.

Jevrejeva, S. and J. C. Moore. 2001. Singular spectrum analysis of Baltic Sea ice conditions and large-scale atmospheric patterns since 1708. Geophys. Res. Lett.,28, 4503-4506.

Johnsen, S. J. 1977. Stable isotope homogenization of polar firn and ice. International Association of Hydrological Sciences Publication 118 (Symposium at Grenoble 1975 - Isotopes and Impurities in Snow and Ice), 210-219.
Johnsen, S. J., H. B. Clausen, K. M. Guffey, G. Hoffmann, J. Schwander and T. Creyts. 2000. Diffusion of stable isotopes in polar firn and ice: the isotope effect in firn diffusion. In Hondoh, T., ed. Physics of ice core records. Sapporo, Hokkaido University Press, 121-140.

Jouzel, J. and 12 others. 1997. On the validity of the temperature reconstruction from water isotopes in ice cores. 7. Geophys. Res., 102(C12), 26,471-26,487.

Kekonen, T., J. Moore, R. Mulvaney, E. Isaksson, V. Pohjola and R. S. W. van de Wal. 2002. An 800 year record of nitrate from the Lomonosovfonna ice core, Svalbard. Ann. Glaciol., 35 (see paper in this volume).

Koerner, R. M. 1977. Distribution of microparticles in a 299-m core through the Devon Island ice cap, Northwest Territories, Canada. International Association of Hydrological Sciences Publication 118 (Symposium at Grenoble 1975 - Isotopes and Impurities in Snow and Ice), 371-376.

Koerner, R. M. 1997. Some comments on climatic reconstructions from ice cores drilled in areas of high melt. F. Glaciol., 43(143), 90-97. (Erratum: 43(144), p. 375-376.)

Legrand, M. and P. Mayewski. 1997. Glaciochemistry of polar ice cores: a review. Rev. Geophys., 35(3), 219-243.

Meese, D. A. and 8 others. 1997. The Greenland Ice Sheet Project 2 depth-age scale: methods and results. 7. Geophys. Res., 102(C12), 26,411-26,423.

Nordli, P. Ä., I. Hanssen-Bauer and E. J. Førland. 1996. Homogeneity analyses of temperature and precipitation series from Svalbard and Jan Mayen. Oslo, Det Norske Meteorologiske Institutt. (DNMI Klima Report 16.)

Nye, J. F. 1963. Correction factor for accumulation measured by the thickness of the annual layers in an ice sheet. F. Glaciol., 4(36), 785-788.

Pälli, A. and 6 others. In press. Spatial and temporal variability of snow accumulation using ground-penetrating radar and ice cores on a Svalbard glacier. 7. Glaciol.

Paterson, W. S. B. 1994. The physics of glaciers. Third edition. Oxford, etc., Elsevier.

Pinglot, J. F. and 6 others. 1999. Investigations of temporal change of the accumulation in Svalbard glaciers deduced from nuclear tests and Chernobyl reference layers. Polar Res., 18(2), 315-321.

Pohjola, V.A. 2002. On the potential to retrieve climatic and environmental information from ice core sites suffering periodic melt, with specific assessment of the Southern Patagonia Ice Field. In Sepúlveda, F., G. Casassa and R. Sinclair, eds. The Patagonia icefields: an unique natural laboratory. New York, Kluwer Academic/Plenum Publishers, 125-138.

Pohjola, V. A. and 7 others. 2002. Effect of periodic melting on geochemical and isotopic signals in an ice core on Lomonosovfonna, Svalbard. $f$ Geophys. Res., 107(D4), 1-14. (10.1029/2000JD000149.

Press, W. H., S. A. Teukolsky, W.T. Vetterling and B. P. Flannery. 1992. Numerical recipes in $C$ : the art of scientific computing. Second edition. Cambridge, Cambridge University Press.

Raymond, C., B. Weertman, L. Thompson, E. Mosley-Thompson, D. Peel and B. Mulvaney. 1996. Geometry, motion and mass balance of Dyer Plateau, Antarctica. 7. Glaciol., 42(142), 510-518.

Shuman, C. A., R. B. Alley, S. Anandakrishnan, J.W. C. White, P. M. Grootes and C. R. Stearns. 1995. Temperature and accumulation at the Greenland Summit: comparison of high-resolution isotope profiles and satellite passive microwave brightness temperature trends. 7. Geophys. Res., 100(D5), 9165-9177.

Thompson, D.W. J. and J.W. Wallace. 1998. The Arctic Oscillation signature in the wintertime geopotential height and temperature fields. Geophys. Res. Lett., 25(9), 1297-1300.

Van de Wal, R. S.W. and 6 others. 2002. Reconstruction of the historical temperature trend from measurements in a medium-length borehole on the Lomonosovfonna plateau, Svalbard. Ann. Glaciol., 35 (see paper in this volume).

Vautard, R., P. Yiou and M. Ghil. 1992. Singular-spectrum analysis: a toolkit for short, noisy chaotic signals. Physica $D, \mathbf{5 8}(1), 95-126$

Whillans, I. M. and P. M. Grootes. 1985. Isotopic diffusion in cold snow and firn. F. Geophys. Res., 90 (D2), 3910-3918. 